\title{
PARCELAMENTO DA COBERTURA NITROGENADA DO ALGODOEIRO ( ${ }^{1}$ )
}

\author{
NELSON MACHADO DA SILVA $\left({ }^{2}\right)$, LUIZ HENRIQUE CARVALHO $\left({ }^{2}, 4\right)$ \\ e NELSON BORTOLETTO $\left(^{3}\right)$
}

\begin{abstract}
RESUMO
São relatados e discutidos resultados de produção obtidos em vinte e quatro ensaios de adubação com o algodoeiro, conduzidos em diferentes solos das principais áreas produtoras paulistas de 1975 a 1984. Para avaliar o efeito da adubação nitrogenada, doses de 0,25 e $50 \mathrm{~kg} / \mathrm{ha}$ de $\mathrm{N}$ foram fornecidas em cobertura logo após o desbaste, 30 a 40 dias após a emergência das plantas. Em três outros tratamentos, a dosagem de $50 \mathrm{~kg} /$ ha de $\mathrm{N}$ foi parcelada, sendo fornecida metade no desbaste e metade em fases posteriores do ciclo, a saber: $45-55,65-75$ e 85-95 dias de idade. Nesses tratamentos, o sulfato de amônio forneceu o nitrogênio. Uma cobertura com uréia (50kg/ha de N), no desbaste, completou o quadro de tratamentos, estudados em esquema de quadrado latino $7 \times 7$. Foram efetuadas análises estatísticas dos dados individuais de produção e análises conjuntas para grupos de ensaios, reunidos em função do tipo de solo e da intensidade de cultivo anterior das glebas. Em linhas gerais, a reaçáo das plantas ao nitrogênio aparentemente se relacionou mais à intensidade de cultivo do solo do que ao fator textura, indicado pelo teor de matéria orgânica, uma vez que os maiores efeitos da adubação nitrogenada ocorreram nos solos intensamente cultivados, independente de
\end{abstract}

(1) Recebido para publicação em 6 de agosto de 1985.

(2) Seção de Algodāo, Instituto Agronômico (IAC), Caixa Postal 28, 13001 Campinas (SP).

(3) Escritório Regional de Votuporanga, IAC.

(4) Bolsista do CNPq. 
sua textura. Cultivado, porém, em solo arenoso, com baixo teor de matéria orgânica, logo após pastagem, o algodoeiro reagiu pouco à adubação nitrogenada. Mesmo no grupo de alta resposta ao nitrogênio, o parcelamento da cobertura deixou de apresentar vantagens sobre a aplicação total por ocasiāo do desbaste. Ademais, houve tendência para queda da produtividade em função do atraso da segunda aplicação. Assim, para algodão cultivado em solos de textura média/argilosa, recomenda-se que a cobertura nitrogenada seja feita após o desbaste, logo que as condiçōes de umidade se mostrem adequadas. Para os solos arenosos, há necessidade de maiores informaçōes, especialmente em glebas de mais intenso cultivo. Da mesma forma, novos estudos devem conferir a pequena vantagem obtida pelo sulfato de amônio sobre a uréia.

Termos de indexação: algodoeiro; nitrogênio; cobertura, parcelamento; solo, intensidade de cultivo, textura.

\section{INTRODUÇÃO}

Em nosso meio, há muito se recomenda que o nitrogênio seja aplicado parceladamente, na cultura algodoeira, parte no plantio e o restante em cobertura, após o desbaste, 30 a 40 dias da emergência das plantas (FUZATTO, 1965). A aplicação total do adubo nitrogenado no sulco de plantio prejudicaria a germinação das sementes e o desenvolvimento inicial do algodoeiro, em especial na seca (NEVES \& FREIRE, 1956, 1957a). Além disso, em condiçōes de precipitação intensa, comum na época de plantio, o nitrogênio ficaria sujeito a perdas, uma vez que o sistema radicular não se acha plenamente formado para o conveniente aproveitamento do adubo (NEVES \& FREIRE, 1957a).

Como a fase de maior intensidade de absorção dos nutrientes do solo ocorre entre os estádios de emissão dos botōes florais e o de pleno florescimento (MENDES, 1960), abrangendo período superior a 30 dias, convém analisar a possibilidade do parcelamento da cobertura, em especial nos solos de textura arenosa.

Dados preliminares obtidos em nosso meio indicam certa vantagem na aplicação dividida (NEVES \& FREIRE, 1957b). Pelo número limitado de locais estudados e pela falta de consistência dos resultados dentro de localidade, os próprios autores sugerem a realização de novos estudos antes de recomendar essa prática. Em regiōes de solos arenosos, intensamente cultivados, no exterior, tem sido aconselhado o parcelamento em até três vezes, buscando evitar deficiência ou excesso de nitrogênio no início do desenvolvimento, assim como deficiência durante o periodo posterior, de maior necessidade (MENDES, 1960). Com o objetivo de obter informaçōes a esse respeito, foram instalados inúmeros experimentos de campo em diferentes solos representativos das principais áreas algodoeiras do Estado de São Paulo, cujos resultados são aqui relatados e discutidos. 


\section{MATERIAL E MÉTODOS}

Entre 1975 e 1984, foram realizados vinte e quatro experimentos de campo com o algodoeiro, em diferentes solos, visando estudar o efeito do parcelamento da cobertura nitrogenada. Em esquema de quadrado latino, doses de 25 (trat ${ }^{\circ}$ 2) e $50 \mathrm{~kg} / \mathrm{ha}$ de $\mathrm{N}$ (trat ${ }^{\circ} 3$ ) - aplicadas em cobertura, no desbaste, ou seja, 30 a 40 dias após a emergência das plantinhas - foram comparadas ao tratamento testemunha (1), para avaliar o efeito do nutriente. Em outros três tratamentos (4, 5 e 6), a dose máxima de adubo foi subdividida, sendo $25 \mathrm{~kg} / \mathrm{ha}$ de $\mathrm{N}$ aplicados na cobertura tradicional e o restante no transcorrer do ciclo da planta, a saber: 45-55, 65-75 e 85-95 dias de idade do algodoeiro. Sulfato de amônio foi o adubo utilizado nos tratamentos descritos. Uma cobertura com uréia (trat ${ }^{\circ} 7$ ), fornecendo $50 \mathrm{~kg} / \mathrm{ha}$ de $\mathrm{N}$ no desbaste, completou a série de tratamentos.

Até o ano agrícola de 1978/79, utilizou-se a adubação básica de plantio de 8-50-50kg/ha, respectivamente, de $\mathrm{N}, \mathrm{P}_{2} \mathrm{O}_{5}$ e $\mathrm{K}_{2} \mathrm{O}$. A partir de então, aumentou-se a adubação para 10-65-65 em solos onde o algodoeiro reagia bem a potássio, e para $8-70-50 \mathrm{~kg} / \mathrm{ha}$ nos solos arenosos, onde o efeito do potássio tem sido menor. Sulfato de amônio, superfosfato triplo e cloreto de potássio forneceram os nutrientes nas adubaçôes anuais de plantio. Até 1977/78, os experimentos foram semeados com a variedade comercial "IAC 16" e a partir de 1978/79, com a "IAC 17", exceto nas glebas com problema de nematóide, onde se usou a "IAC 19".

Em caráter exploratório, o estudo teve início em Latossolo Roxo (BRASIL, 1960), rico em matéria orgânica e, conseqüentemente, em argila (LEPSCH et alii, 1982), intensamente cultivado e adubado, no municipio de Campinas. Com o passar dos anos, estendeu-se para Latossolo Roxo medianamente cultivado e adubado, no município de Araras, e a outros tipos, como Latossolo Vermelho-Escuro e Latossolo Vermelho-Amarelo, nos municipios de Aguai, Paranapanema, Moji Mirim e Leme, e para solos arenosos da zona oeste paulista - onde o algodoeiro costumeiramente é plantado em rotação com pastagens - nos municípios de Presidente Venceslau, Álvares Florence, Dracena e Votuporanga. Por falta de instrumentação adequada nas diversas localidades estudadas, não foi computada a precipitação pluvial nas aplicaçōes de nitrogênio.

A parcela experimental constou de quatro linhas de $5 \mathrm{~m}$ de comprimento, espaçadas de 0,75 e $1,00 \mathrm{~m}$, conforme o nivel de fertilidade local do solo. Após a operação de desbaste, foram mantidas, em média, sete plantas por metro. Os adubos nitrogenados aplicados em cobertura foram distribuídos em faixas distantes cerca de $0,15 \mathrm{~m}$ da linha das plantas, conforme é costume na cultura algodoeira (RIGHI et alii, 1965). A colheita do algodão foi feita nas linhas centrais das parcelas experimentais. $O$ presente trabalho versa sobre os dados de produção de algodão em caroço. Efetuaram-se as análises estatísticas por experimento, dando-se, porém, maior ênfase a análises conjuntas, quando os ensaios foram reunidos em função do histórico da gleba e do tipo de solo. Quanto ao primeiro 
aspecto, foram considerados solos intensamente cultivados aqueles plantados e adubados por mais de quinze anos (ensaios 1 a 10); medianamente cultivados, aqueles plantados e adubados por mais de cinco e menos de quinze anos (ensaios 11 a 14) e solos pouco cultivados ou descansados, aqueles cultivados e adubados por menos de cinco anos (ensaios 15 a 24). Quanto a tipo de solo, considerou-se, além do grande grupo (BRASIL, 1960), seu teor de matéria orgânica, que indiretamente pode indicar a concentraçāo de argila (LEPSCH et alii, 1982). As amostras de terra foram analisadas, ainda, para $\mathrm{pH}$ em água, $\mathrm{P}\left(\mathrm{H}_{2} \mathrm{SO}_{4}\right.$, $0,05 \mathrm{~N}$ ), $\mathrm{Ca}, \mathrm{K}$ e Mg; nas análises dos ensaios mais recentes (após 1982), foi determinado o $\mathrm{pH}$ em CaCl${ }_{2}$ e extraiu-se $\mathrm{P}$ pela resina trocadora de ânions. Os dados médios de produção, quer nas análises individuais, quer nas conjuntas, foram comparados pelo teste de Duncan, a $5 \%$.

\section{RESULTADOS}

No quadro 1 encontram-se os dados médios de produção de algodão em caroço obtidos por experimento e os respectivos resultados da análise estatística.

Nos dados dos primeiros quatorze ensaios, conduzidos em solos intensa ou medianamente cultivados e adubados, conforme já descrito, nota-se que, em $79 \%$ dos casos, foi obtida diferença significativa entre médias de tratamentos, segundo indicam os correspondentes valores de "F". Em apenas um desses ensaios a dose máxima aplicada totalmente em cobertura no desbaste (trat ${ }^{\circ} 3$ ) não diferiu da testemunha (ensaio 9), pelo teste de Duncan a 5\%, enquanto em cinco casos $(45 \%)$, nos ensaios $5,6,7,11$ e 14 , superou inclusive a dose intermediária (trat ${ }^{\circ}$ 2), configurando alta resposta das plantas à adubação nitrogenada.

Quanto ao parcelamento da cobertura, em apenas um dos onze casos $(9 \%)$, no ensaio 13 , houve vantagem da aplicação dividida de nitrogênio, quando a complementação aos 65-75 dias (trat ${ }^{\circ} 5$ ) proporcionou acréscimo de $20 \%$ sobre a produção das plantas com cobertura única no desbaste (trat ${ }^{\circ} 3$ ). Em contrapartida, também em um só caso (ensaio 7), um dos parcelamentos (trat ${ }^{\circ} 4$ ) proporcionou produção menor $\left(9 \%\right.$ ) do que a cobertura única (trat ${ }^{\circ} 3$ ), diferença essa também estatisticamente significativa.

Observou-se, por outro lado, certa tendência para maior produtividade das plantas quando adubadas com sulfato de amônio na dose máxima de nitrogênio (trat ${ }^{\circ} 3$ ). No entanto, esse adubo superou estatisticamente a uréia (trat ${ }^{\circ} 7$ ) em apenas dois casos (18\%), nos ensaios 6 e 11, quando proporcionou acréscimos de produtividade de 11 e $12 \%$ respectivamente. 


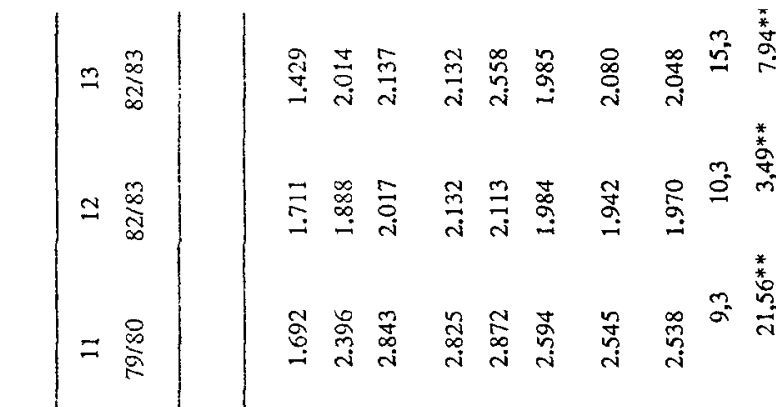

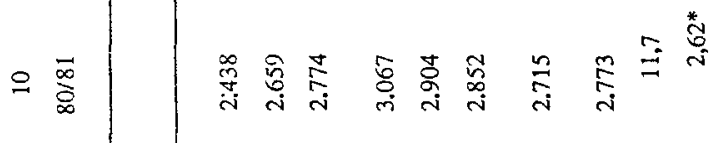

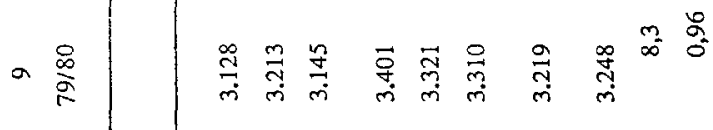

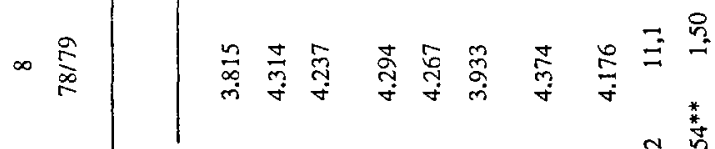

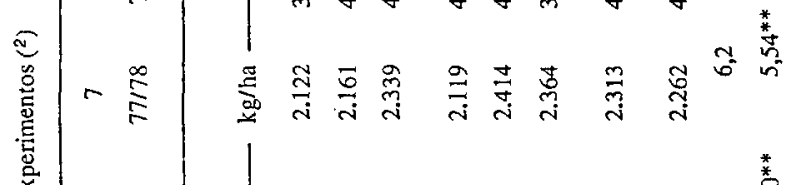

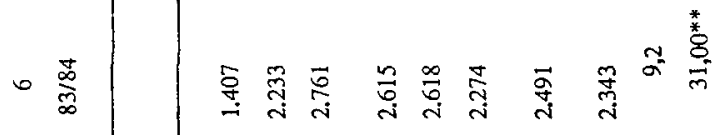

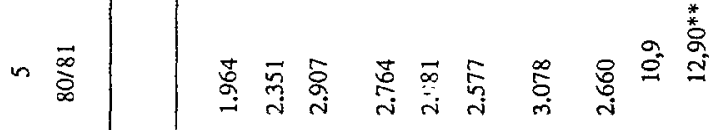

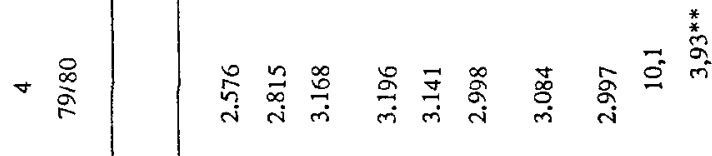

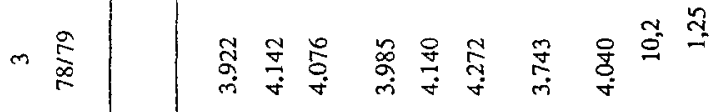

$$
\begin{aligned}
& \text { N }
\end{aligned}
$$

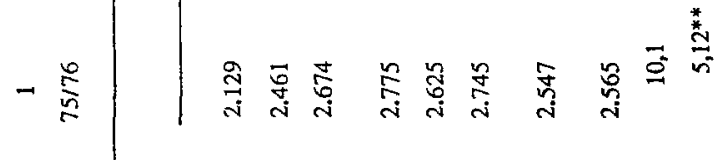

$$
\begin{aligned}
& \text { | }
\end{aligned}
$$




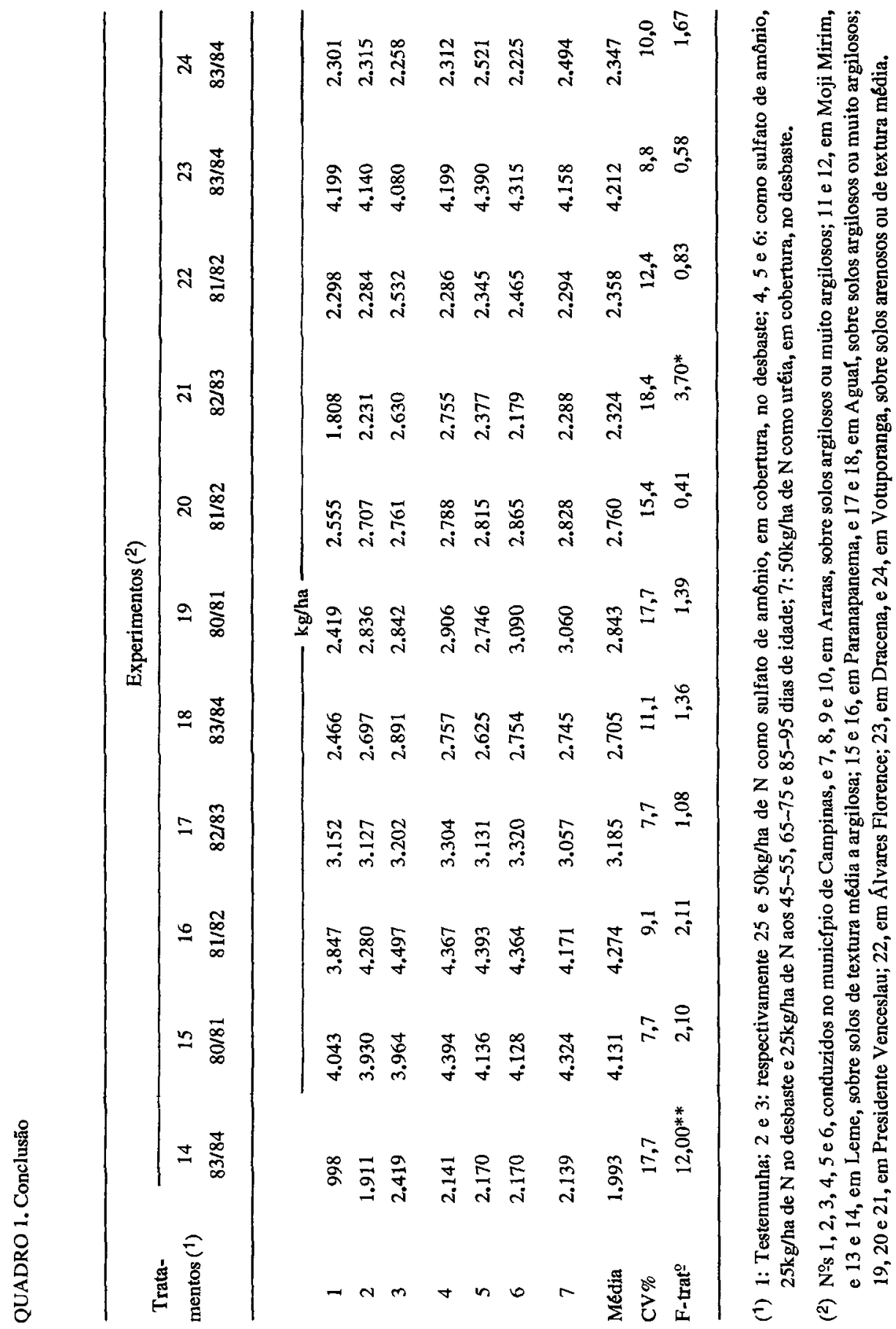


Os solos das áreas representativas dos últimos dez ensaios, por sua vez, eram medianamente ou pouco cultivados e adubados, estando, em alguns casos, cobertos por pastagem, ou seja, em relativo repouso para a cultura algodoeira (FUZATTO, 1965). Nessa série, foi observado valor significativo de F-tratamentos em um único ensaio (10\%), o de número 21 , onde somente a cobertura única no desbaste (trat ${ }^{\circ} 3$ ) superou estatisticamente a testemunha, não diferindo, entretanto, dos demais tratamentos. No referido local, o algodoeiro estava sendo plantado pela terceira vez sucessiva após vários anos de solo coberto com pastagem.

$\mathrm{Na}$ tentativa de obter maior consistência nos resultados, os experimentos foram reunidos por tipo de solo, pelo teor de argila e pela intensidade de cultivo, conforme considerado em capítulo anterior. No quadro 2, é apresentada uma variação dos resultados de análise de solo de amostras extraídas durante os anos de experimentação, dentro de cada grupo.

QUADRO 2. Variação dos resultados de ańlises químicas de solo observada durante os anos de condução dos ensaios de parcelamento da cobertura nitrogenada do algodoeiro, nos grupos de experimentos constituídos em funçāo do teor aproximado de argila do solo e da intensidade de cultivo das glebas

\begin{tabular}{|c|c|c|c|c|}
\hline \multirow{2}{*}{$\begin{array}{l}\text { Análise } \\
\text { de } \\
\text { solo (1) }\end{array}$} & \multicolumn{4}{|c|}{ Grupo de experimentos $\left({ }^{2}\right)$} \\
\hline & A & B & $\mathrm{C}$ & $\mathrm{D}$ \\
\hline $\mathrm{pH}\left(\mathrm{H}_{2} \mathrm{O}\right)$ & $5,6-7,1$ & $5,6-6,2$ & $5,5-5,9$ & 6,0 \\
\hline $\mathrm{pH}\left(\mathrm{CaCl}_{2}\right)$ & $5,0-5,1$ & 5,0 & $4,8-5,7$ & $4,7-6,0$ \\
\hline M.O. \% & $3,1-4,8$ & $3,6-4,1$ & $0,9-2,0$ & $1,7-2,5$ \\
\hline $\mathrm{P}\left(\mathrm{H}_{2} \mathrm{SO}_{4}\right)-\mu \mathrm{g} / \mathrm{cm}^{3}$ & $7-13$ & $23-29$ & $4-17$ & 12 \\
\hline $\mathbf{P}($ resina $)-\mu \mathrm{g} / \mathrm{cm}^{3}$ & $32-46$ & $100-146$ & $6-28$ & $15-44$ \\
\hline $\mathrm{K}-\mathrm{meq} / 100 \mathrm{~cm}^{3}$ & $0,18-0,43$ & $0,19-0,31$ & $0,13-0,25$ & $0,10-0,36$ \\
\hline $\mathrm{Ca}-\mathrm{meq} / 100 \mathrm{~cm}^{3}$ & $2,3-7,4$ & $3,8-5,0$ & $0,8-2,4$ & $1,8-4,2$ \\
\hline $\mathrm{Mg}-\mathrm{meq} / 100 \mathrm{~cm}^{3}$ & $0,7-2,0$ & $0,4-0,7$ & $0,5-0,9$ & $0,5-1,7$ \\
\hline
\end{tabular}

(1) As determinaçōes de pH e de $\mathrm{P}$, por mettodos diferentes, não săo coincidentes, pois se referem a amostras diversas.

(2) Grupo A (ensaios 15 a 18) e grupo B (ensaios 1 a 10), de solos argilosos/muito argilosos, em ordem mediana a intensamente cultivados e adubados; grupo $C$ (ensaios 15 a 24), de solos arenosos ou de textura média, em pousio ou pouco cultivados, e grupo $D$ (ensaios 11 a 14), de solos de textura média a argilosa, intensamente cultivados.

De modo geral, as glebas estudadas apresentavam-se em faixas de $\mathrm{pH}$ razoáveis para o cultivo do algodoeiro. Nos solos mais argilosos, pertencentes aos grandes grupos de Latossolo Vermelho-Escuro (Grupo A) e Latossolo Roxo (Grupo B), observa-se que o teor de fósforo aumenta do primeiro para o segundo, indicando a maior intensidade de cultivo e de adubação anteriores nas glebas 
deste último. O mesmo ocorre no grupo de solos de textura mais leve, onde o teor de fósforo cresce dos solos arenosos (Grupo C), menos adubados, para os de textura média, mais intensamente trabalhados (Grupo D).

$\mathrm{Na}$ figura 1 encontram-se os resultados médios de produção de algodāo obtidos por grupos de experimentos, assim como os de análises estatísticas conjuntas.
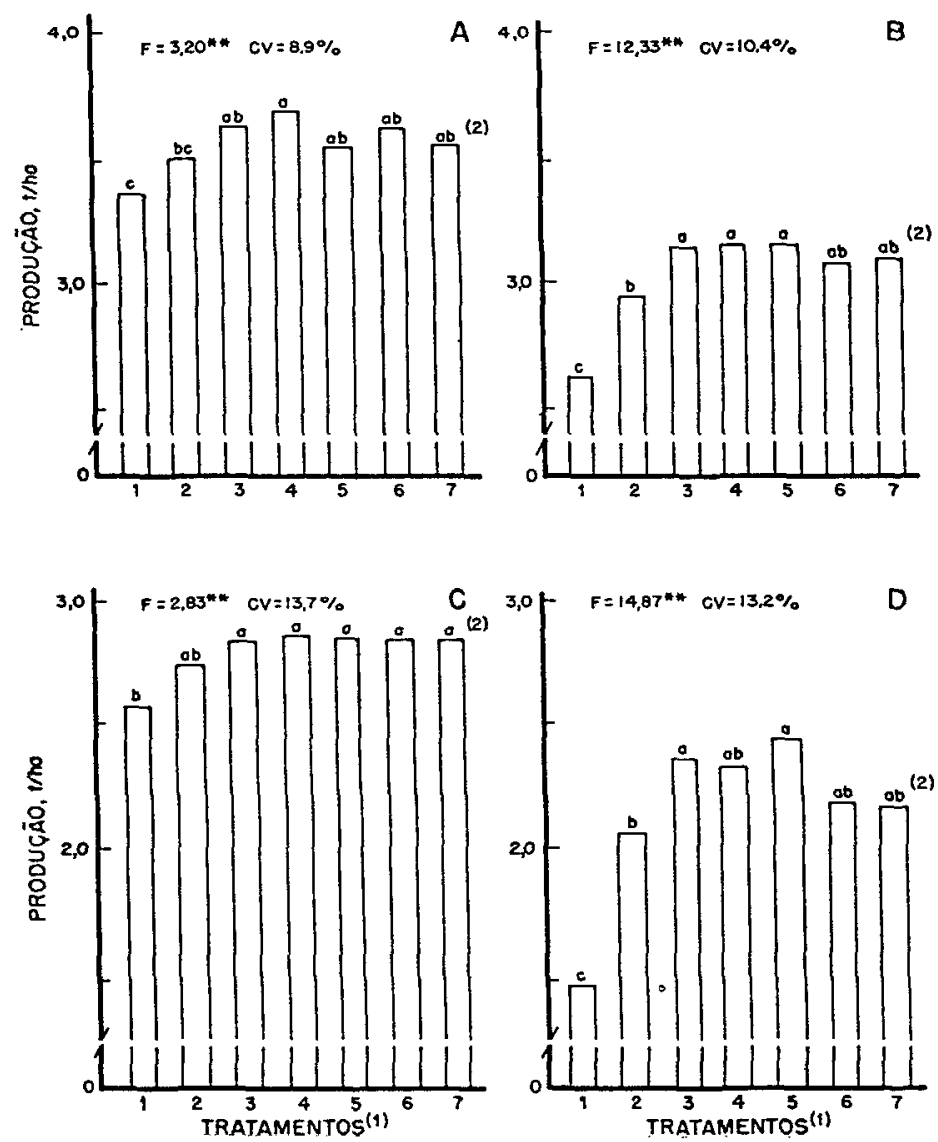

FIGURA 1. Resultados médios de produçāo de algodão em caroço obtidos em grupos de ensaios reunidos por tipo de solo e intensidade de plantio das glebas:

( $\left.{ }^{1}\right)$ Tratamentos: 1. Testemunha; 2. Sulfato de amônio, $25 \mathrm{~kg} /$ ha de $\mathrm{N}$, no desbaste; 3. S. amônio, $50 \mathrm{~kg} /$ ha de $\mathrm{N}$, no desbaste; 4. S. amônio, $25 \mathrm{~kg} /$ ha no desbaste e $25 \mathrm{~kg} / \mathrm{ha}$ aos $45-55$ dias; 5 . S. amônio, $25 \mathrm{~kg} /$ ha no desbaste e $25 \mathrm{~kg} / \mathrm{ha}$ aos $65-75$ dias; 6 . S. amônio, $25 \mathrm{~kg} / \mathrm{ha}$ no desbaste e $25 \mathrm{~kg} / \mathrm{ha}$ aos $85-95$ dias; 7 . Uréia, $50 \mathrm{~kg} / \mathrm{ha}$ de $\mathrm{N}$ no desbaste. (2) Teste de Duncan a 5\%. 
Em solos argilosos/muito argilosos (M.O.: 3,1-4,8\%), pertencentes ao grande grupo de Latossolo Vermelho-Escuro, medianamente cultivados (Fig. 1-A), a produtividade média da testemunha alcançou o altíssimo índice de $3.376 \mathrm{~kg} / \mathrm{ha}$ de algodão em caroço, o que demonstra a boa disponibilidade natural de nitrogênio para o algodoeiro. Apesar disso, a cobertura nitrogenada na dose máxima (50kg/ha de N), independente da época, do modo de aplicação e do tipo de adubo, proporcionou acréscimos significativos na produtividade, de 6 a $10 \%$. Observou-se um pequeno destaque para o tratamento 4 , onde parte da dose de cobertura foi cedida aos 45-55 dias, sendo o único que estatisticamente superou a dose intermediária de nitrogênio, cedida no desbaste (trato 2 ).

Ainda em solos argilosos/muito argilosos (M.O.: 3,6-4,1\%), pertencentes ao grande grupo de Latossolo Roxo, intensamente cultivados (Fig. 1-B), o efeito da adubação nitrogenada foi bem mais destacado. Assim, a dose de $25 \mathrm{~kg} / \mathrm{ha}$ de $\mathrm{N}$ aplicada no desbaste (trat ${ }^{\circ}$ 2) proporcionou acréscimo significativo $(12 \%)$ sobre a produção da testemunha ( $2653 \mathrm{~kg} / \mathrm{ha}$ de algodão em caroço), enquanto os três tratamentos (n-s 3, 4 e 5), fornecedores da dose máxima ( $50 \mathrm{~kg} / \mathrm{ha}$ de $\mathrm{N}$ ), superaram estatisticamente a anterior, configurando tendência para reação linear do algodoeiro à adubação. $A$ despeito disso, nāo houve qualquer vantagem de parcelar a cobertura, uma vez que a produtividade dos tratamentos 4 e 5 foi praticamente igual à do 3, e que a aplicação parcelada feita tardiamente, aos 85-95 dias de idade (trat ${ }^{\circ} 6$ ), esteve um pouco abaixo dos niveis dos demais tratamentos com dose máxima ( $50 \mathrm{~kg} / \mathrm{ha}$ de $\mathrm{N}$ ). $\mathrm{O}$ uso da ure̊ia (trat ${ }^{\circ} 7$ ), quando comparado à correspondente dose $(50 \mathrm{~kg} / \mathrm{ha}$ de $\mathrm{N})$ de sulfato de amônio (trat $\left.{ }^{\circ} 3\right)$ conduziu, também, a um pequeno decréscimo de produção.

Em solos de textura média/argilosa (M.O.: 1,7-2,5\%), do grande grupo Latossolo Vermelho-Amarelo, intensamente cultivados (Fig. 1-D), 0 efeito do nitrogênio foi excepcional, tendo as doses de 25 e $50 \mathrm{~kg} / \mathrm{ha}$ de $\mathrm{N}$ aplicadas em cobertura, no desbaste (traț-s 2 e 3 ) proporcionado acréscimos respectivos de 41 e $61 \%$ sobre a produtividade da testemunha (1.458kg/ha de algodão em caroço). Embora a diferença entre as referidas doses tenha sido estatisticamente significativa, evidenciando tendência para efeito linear de nitrogênio, não foi observada vantagem do parcelamento da cobertura nitrogenada. Aliás, como na série anterior de ensaios (Fig. 1-B), nota-se que o parcelamento tardio, com a segunda aplicação efetuada aos 85-95 dias (trato 6), levou a um pequeno decréscimo de produção $(7 \%)$ quando comparado à aplicação total em cobertura, no desbaste (trat ${ }^{\circ} 3$ ). Da mesma forma, a cobertura com uréia (trato 7 ) foi levernente inferior (8\%) à correspondente com sulfato de amônio (trat 3 ).

Em solos arenosos/textura média (M.O: 0,9-2,0\%) da região oeste paulista, onde tradicionalmente o algodoeiro tem sido cultivado em rotação com pastagem, o efeito da adubação nitrogenada foi o mais baixo dos diversos grupos de ensaios. Para um bom nivel de produtividade, de $2,597 \mathrm{~kg} / \mathrm{ha}$ de algodão em caroço, 
observado em média para o tratamento sem nitrogênio, o único efeito estatisticamente significativo foi devido aos tratamentos com a dose de $50 \mathrm{~kg} / \mathrm{ha}$ de $\mathrm{N}(3$, $4,5,6$ e 7 ), correspondendo a um acréscimo de $10 \%$ aproximadamente (Fig. 1-C).

\section{DISCUSSĀO E CONCLUSÕES}

A resposta do algodoeiro à adubação nitrogenada é função de uma série de fatores, como intensidade de cultivo e adubação, tipo de solo, umidade, natureza da variedade, incidência de pragas e moléstias, que, no conjunto, constituem o que se convencionou chamar de potencial de produção das glebas. Quanto maior esse potencial - representado pelo cultivo de variedades selecionadas, semeadas em época e espaçamento adequados, com eficaz controle de pragas, sobre solo bem adubado e sem problemas de doenças e nematóides - maior será a eficiência da adubação nitrogenada, em especial nos solos de textura mais arenosa, intensamente trabalhados (FUZATTO, 1965, e TUCKER \& TUCKER, 1968).

Cultivando variedades selecionadas em diferentes tipos de solos, na presente série de experimentos, observou-se que a reação do algodoeiro à adubação nitrogenada esteve mais relacionada à intensidade de cultivo das glebas do que ao teor de argila dos solos. Com efeito, nos solos ricos em argila, cultivados e adubados por mais de quinze anos (Fig. 1-B), o efeito médio do nitrogênio foi mais destacado do que nas glebas menos exploradas (Fig. 1-A), dentro de valores de matéria orgânica do solo semelhantes. Nos solos de textura média para arenosos, a importância da intensidade de cultivo anterior destacou-se ainda mais. Assim, o algodoeiro apresentou pequena reação a nitrogênio nos solos arenosos, pobres em matéria orgânica, quando cultivado após pastagem (Fig. 1-C), enquanto em glebas de textura média (Fig. 1-D), com teor de matéria orgânica mais elevado, porém intensamente cultivadas, o efeito de $\mathrm{N}$ foi excepcional.

O parcelamento da cobertura nitrogenada, por sua vez, não se mostrou eficiente nem mesmo nos solos de textura média, intensamente cultivados (Fig. 1-D), onde a resposta da planta foi excepcional. Para os casos isolados de efeito positivo (ensaio 21) e prejudicial do parcelamento (ensaio 7), não se encontrou, junto aos dados coletados, explicação plausivel. De qualquer modo, obsenou-se uma tendência para queda da produtividade do algodoeiro quando a segunda cobertura foi efetuada tardiamente (85-95 dias da emergência), conforme se observa nos ensaios dos grupos de mais alta resposta a nitrogênio (Fig. 1-B e D), conduzidos em solos de textura média a argilosa. Isso reforça a opinião de que a cobertura nitrogenada em épocas tardias é desaconselhável, por estimular o crescimento vegetativo em detrimento da carga (FUZATTO, 1965), nos referidos solos. Dada a baixa reação das plantas à adubaçāo nitrogenada em solos arenosos, há necessidade de novos estudos, especialmente em glebas de mais intenso cultivo. 
A tendência para maior produtividade do algodoeiro ao receber cobertura com sulfato de amônio (trat ${ }^{\circ} 3$ ), em vez de uréia (trat ${ }^{\circ} 7$ ), como se observa em alguns ensaios individuais e na série de maior resposta a nitrogênio (Fig. 1-D), pode ser atribuída ao fornecimento de enxofre. O uso, no plantio, de mistura de adubos isenta de enxofre, a alta concentração de S no sulfato de amônio (24\%) e a freqüência com que se tem observado efeito significativo desse nutriente na adubaçāo do algodoeiro (FREITAS et alii, 1960, McCLUNG et alii, 1961, MIKKELSEN et alii, 1963, e SILVA et alii, 1981), reforçam a hipótese levantada. Entretanto, considerando que a diferença de produtividade entre os adubos foi pequena, em média ao redor de $8 \%$, que o preço do nitrogênio da uréia é inferior ao do sulfato de amônio e que o enxofre pode ser eficientemente cedido no adubo de plantio (SILVA et alii, 1981), há necessidade de estudos complementares para esclarecer melhor a importância dos referidos adubos.

\section{SUMMARY \\ EFFECT OF SPLIT APPLICATION OF NITROGEN ON YIELD OF COTTON}

The advantage of parcelling out the side dressed nitrogen in cotton crop was studied in twenty four-field experiments, conducted on different soils of the major producting regions of the State of São Paulo, Brazil, during the period from 1975 to 1984 . Doses of 0,25 , and $50 \mathrm{~kg} / \mathrm{ha}$ of $\mathrm{N}$ were side dressed, just after thinning, with the purpose of studying the effect of rate of nitrogen application. In other three treatments, the highest dose was splitted, half at thinning and half at delayed stages, at 45-55, 65-75 and 85-95 days after plant emergency. Ammonium sulphate was used in those treatments. In an extra treatment urea was side dressed at thinning at the rate of $50 \mathrm{~kg} / \mathrm{ha}$ of $\mathrm{N}$. A Latin square experimental design was used. Generally the effect of nitrogen on cotton yield was related more with the intensity of previous cultivation than with soil texture. Cotton grown after pasture, on sandy soils, presented low response to nitrogen application, whereas on sandy-clay and heavy-clay soils intensely cultivated, the effect of nitrogen fertilization was positive and highly significant. Split application of nitrogen did not show any advantage over one side dressing even in the groups of soils of high response to fertilization. Otherwise, a tendency to lower yields was observed with the delay of the split application. Thus, for cotton grown on sandy-clay and heavy-clay soils, it is recommended that the nitrogen be side dressed just after thinning, provided that the soil moisture is adequate. Further studies are needed on the use of nitrogen fertilizers on sandy soils.

Index terms: cotton; nitrogen; split application; soil cultivation, intensity; soil texture.

\section{AGRADECIMENTOS}

Agradecemos a colaboração prestada aos Srs. Arnaldo Bonomi, Achilis Biazotto e Takemi Haga e filhos; ao Engenheiro Guilherme Rehder, a Da. Clara C. Canto e aos Engenheiros-Agrônomos José Viotti, Amando Le Vocci, Nicanor de Carvalho, José Cassimiro O. Silveira e Marcos V. Justo. 


\section{REFERÊNCIAS BIBLIOGRÁFICAS}

BRASIL. Ministério da Agricultura. Serviço Nacional de Pesquisas Agronômicas. Comissão de Solos. Levantamento de reconhecimento dos solos do Estado de São Paulo. Rio de Janeiro, 1960. 634p. (Boletim do Serviço Nacional de Pesquisas Agronômicas, 12)

FREITAS, L.M.M.; McCLUNG, A.C. \& LOTT, W.L. Experimentos de adubação em dois solos de campo cerrado. São Paulo, IBEC Research Institute, 1960. 19p. (Boletim, 21)

FUZATTO, M.G. Adubação mineral. In:CULTURA e adubação do algodoeiro. São Paulo, Inst. Bras. de Potassa, 1965. p.475-508.

LEPSCH, I.F.; SILVA, N.M. \& ESPIRONELO, A. Relação entre matêria orgânica e textura de solos sob cultivo de algodão e cana-de-açúcar, no Estado de São Paulo. Bragantia, Campinas, 41(8):231-236, 1982.

MENDES, H.C. Nutrição do algodoeiro. II. Absorção mineral por plantas cultivadas em soluçōes nutritivas. Bragantia, Campinas, 19:435-458, 1960.

McCLUNG, A.C.; FREITAS, L.M.M.; MIKKELSEN, D.S. \& LOTT, W.L. A adubação do algodoeiro em solos de campo cerrado no Estado de São Paulo. São Paulo, IBEC Research Institute, 1961. 35p. (Boletim, 27)

MIKKELSEN, D.S.; FREITAS, L.M.M. \& McCLUNG, A.C. Efeitos da calagem e adubação na produção de algodão, milho e soja em três solos de campo cerrado. São Paulo, Instituto de Pesquisa IRI, 1963. 48p. (Boletim, 29)

NEVES, O.S. \& FREIRE, E.S. Adubação do algodoeiro. I. Influência dos adubos, quando aplicados em contato com as sementes, sobre a germinação. Bragantia, Campinas, 15:301-314, 1956.

— \& - _ Adubação do algodoeiro. III. Ensaios sobre a aplicação de azoto em cobertura. Bragantia, Campinas, 16(16):223-242, 1957a.

\& — Adubação do algodoeiro. IV. Ensaios sobre época de aplicação de azoto e potássio. Bragantia, Campinas, 16(20):269-296, $1957 \mathrm{~b}$.

RIGHI, N.R.; FERRAZ, C.A.M. \& CORREA, D.M. Cultura. In: CULTURA e adubação do algodoeiro. São Paulo, Inst. Bras. de Potassa, 1965. p.255-317.

SILVA, N.M.; RODRIGUES FILHO, F.S.O. \& HIROCE, R. Uso de misturas de adubos contendo ou não enxofre na adubaçāo do cultivar IAC 16 de algodoeiro. Bragantia, Campinas, 40(16): 167-168, 1981.

TUCKER, T.C. \& TUCKER, B.B. Nitrogen nutrition. In: ADVANCES in production and utilization of quality cotton: principles and practices. Ames, lowa Sta. Univ. Press, 1968. p.183-211. 